\title{
Comparative Study of Lateral Sphincterotomy versus Local $2 \%$ Diltiazem Ointment for the Treatment of Chronic Anal Fissure
}

\author{
Dr Shib Shankar Kuiri ${ }^{1}$, Dr. Ashis Kumar Saha ${ }^{1}$, Dr Goutam Ghosh ${ }^{2}$, \\ Dr Nilay Mandal ${ }^{1}$, Dr. Bikash Ghosh ${ }^{2}$, Dr Sankha Suvra Ganguly ${ }^{1}$, \\ Dr. Chhanda Das. \\ ${ }^{1}$ Departmen of Surgery, Bankura Sammilani Medical College, Bankura, India \\ ${ }^{2}$ Department of Surgery, R.G.Kar Medical College, Kolkata, India \\ ${ }^{3}$ Department of Pathology, R.G.Kar Medical College, Kolkata, India
}

\begin{abstract}
A chronic anal fissure is a non-healing linear tear in the distal anal mucosa below the dentate line and is a painful entity. A fissure is defined as chronic when it fails to heal within 6 weeks from an acute attackl. This study is an attempt to compare efficacy of lateral internal sphincterotomy versus topical $2 \%$ Diltiazem ointment for the treatment of chronic anal fissure. This prospective comparative study was done in our hospital during one and half year from February'11 to August'12. 50 patients were treated with $2 \%$ Diltiazem ointment and rest 50 underwent lateral internal sphincterotomy for chronic anal fissure. Patients were followed for 8 weeks and thereafter evaluated for symptoms relief in both the groups. Observations were recorded at $2 \mathrm{nd}$, 4th, 6th and 8th week regarding relief of symptoms like pain, bleeding per rectum, healing of ulcer and side effects of fecal incontinence in surgical group. All data were collected and analyzed accordingly. It revealed that $56 \%$ were male and $44 \%$ were female and maximum numbers of patients were in the age group 30-39 years. The chief complaints of patients at presentation-29\% had pain during defecation with constipation, $22 \%$ bleeding per rectum and $49 \%$ had only pain during defecation. Most of them (90\%) had posterior anal fissure. Most of the patients (63\%) had ulcer only. But in $37 \%$ of cases there were ulcer with sentinel piles. Lateral internal sphincterotomy is the treatment of choice while treating chronic anal fissure, because of its simplicity, better healing rates, better patient satisfaction, minimal morbidity and low complication rates. Taking this option also helps the patient to resume his/her normal works earlier than that of topical $2 \%$ Diltiazem ointment.
\end{abstract}

Keywords- Lateral internal sphincterotomy, 2 \% Diltiazem ointment, chronic anal fissure.

\section{INTRODUCTION}

A chronic anal fissure is a crack in the distal anal mucosa which often does not heal after an acute attack. Apart from it being a painful condition it has different modes of presentation such as bleeding per rectum, pain during defecation and pain during defecation with constipation. There are several factors for the development of chronic anal fissure like internal sphincter hypertonia, trauma due to passage of hard stools or diarrhoea episodes, paucity of blood supply, especially the posterior commissure, by the compression of inferior rectal artery. The paucity of blood flow prevents healing of anal fissure until the cycle of internal sphincter hypertonia and decreased blood flow is broken by muscle relaxants or surgery. There are different non-surgical treatments for chronic anal fissure including $2 \%$ Diltiazem ointment topical application and also there are different surgical interventions including lateral internal sphincterotomy. The study was designed to compare the effect of medical management with topical $2 \%$ Diltiazem ointment and surgical treatment by lateral internal sphincterotomy in case of chronic anal fissure with regards to ulcer healing, pain reduction, cessation of bleeding per rectum and incontinence.

\section{AIMS \& OBJECTIVES}

The main objective of this study is to compare the effectiveness and morbidity of surgical (Lateral Internal Sphincterotomy) versus chemical sphincterotomy (by local $2 \%$ Diltiazem) in the treatment of chronic anal fissure.

\section{MATERIALS \& METHODS}

Source of Data: All the data were collected from the patients who were admitted in the wards with chronic anal fissure for Lateral Internal Sphincterotomy (LIS) and patient who attended surgical out-patient department with chronic anal fissure and who will be treated with chemical sphincterotomy by the means of local $2 \%$ Diltiazem. 


\section{Inclusion Criteria}

1. All the cases of anal fissure for more than 6 weeks.

2. Anal fissure associated with sentinel piles and exposure of internal fibres which suggests chronicity.

3. Patients operated following failure of treatment with topical $2 \%$ Diltiazem.

\section{Exclusion Criteria}

1. Those patients with secondary fissures,

2. Fissures complicated with fistula and anal stenosis,

3. Patients with previous ano-rectal surgery,

4. Patients with other co-morbid systemic diseases interfering with wound healing such as diabetes mellitus, malignancies, long term steroid therapy etc.

\section{Study Type}

This is a prospective comparative study of management of chronic anal fissure done in our hospital during a period of one and half year (February'11 to August'12).

\section{Study Area}

Department of General Surgery, B.S.Medical College and Hospital, Bankura, W.B.

Sample \& Sampling Technique

Total 100 patients were randomised into 2 groups, each group containing 50 patients. 50 patients had undergone Lateral Internal Sphincterotomy whereas rest 50 were treated with topical $2 \%$ Diltiazem ointment.

\section{Method of Data Collection}

Patients were selected obeying inclusion and exclusion criteria and divided into two groups of 50 patients in each group. Informed written consent were obtained from the patients after full explanation of the details of the disease process, options of treatment, ultimate outcome, possible side effects, complication and chances of recurrence in either procedure. They were informed of their right to withdraw from the trial at any stage. One group of patients had undergone Lateral Internal Sphincterotomy (LIS) by open method and the other group was treated with $2 \%$ Diltiazem ointment which was applied locally to the distal anal canal thrice daily. In surgical group, the patients were operated after complete pre-operative evaluation. The patients of both the groups were followed up at 2nd, 4th, 6th and 8th week and pain relief, fissure healing, compliance and continence scores were evaluated during each follow up.

Data Analysis

Data was entered in MS-Excel spread sheet. Two groups were compared in relation to the outcome of treatment using $\mathrm{T}$ test and Chi-Square test.

\section{RESULTS \& ANALYSIS}

Total 100 patients with chronic anal fissure were included in this study of which 56 were male and 44 were female patients. The patients were randomized into two groups according to randomization table. Group 1 consisting of 50 patients were treated with medical management by application of $2 \%$ Diltiazem ointment. Group 2 consisting of 50 patients underwent surgical management by lateral internal sphincterotomy. The sex distribution was male dominated: $56 \%$ male and $44 \%$ female and majority of the patients were in the age group of 30-39 years. The presentation was ulcer with sentinel piles in $37 \%$ cases and ulcer only in $63 \%$ cases.

\section{Duration of Symptoms}

All the patients presented had duration of symptoms more than 6 weeks.

Comparison of Symptoms in Both Groups

Among all the patients presented $29 \%$ of the patients had pain during defecation with constipation, 22 $\%$ had bleeding per rectum and $49 \%$ patients had pain during defecation.

Anal Fissure Site The site of anal fissure was posterior in $90 \%$ and anterior in $10 \%$ cases. All the patients were followed up at 2 weeks interval up to 2 months and were evaluated at $2 \mathrm{nd}$, 4th, 6 th and $8^{\text {th }}$ week regarding the outcome of two modalities of treatment in terms of healing of ulcer, pain relief, cessation of bleeding per rectum and incontinence.

\section{Comparison of Pain Relief in Both Groups at Different weeks of Follow Up}

Pain relief was more in surgical treatment group than in medical treatment group at 8th week of follow up. Significant pain relief was seen in both the groups as duration progresses from 2 nd to 8 th week. 


\section{Comparison of Bleeding in Both Groups at Different Weeks of Follow Up}

Proportion of cases with bleeding per rectum was similar in both medical and surgical management group at 2 nd and 4 th week. Bleeding per rectum was not reported by any patients of both groups at 6th weeks and onwards during follow up.

\section{Comparison of Healing of Ulcer in Both Groups at Different Weeks of Follow Up}

Ulcer healing at 8th week was significantly higher in surgical treatment group $(96.0 \%)$ than that of in medical treatment group $(76.0 \%)$. In ulcer healing surgical treatment was almost 8 times more efficacious than medical treatment at 8 th week.

Significant healing of tissue was seen in both the treatment group as duration progresses from 2 nd to 8th week but healing was more in surgical treatment group. No incontinence was present in medical treatment group throughout the study period. But 3 patients among surgical treatment group had faecal incontinence in 1st 6 weeks and by the end of $8^{\text {th }}$ week only 1 patient had frank faecal incontinence.

\section{FIGURES AND TABLES}

Table - 1: Distribution of patients with chronic anal fissure according to treatment group and bleeding per rectum at four weeks

\begin{tabular}{|l|l|l|}
\hline \multicolumn{1}{|c|}{$\begin{array}{c}\text { Treatment group Bleeding } \\
\text { present }\end{array}$} & $\begin{array}{c}\text { Bleeding present } \\
\text { No. }(\%)\end{array}$ & $\begin{array}{c}\text { Bleeding absent } \\
\text { No. }(\%)\end{array}$ \\
\hline Medical 2 & $\mathbf{2 ( 4 . 0 )}$ & $\mathbf{4 8}(96.0)$ \\
\hline Surgical 2 & $\mathbf{2 ( 4 . 0 )}$ & $\mathbf{4 8}(96.0)$ \\
\hline Fisher's Exact p & 1.00 & \\
\hline
\end{tabular}

Table-2: Distribution of patients with chronic anal fissure according to treatment group and ulcer healing at 8th weeks

\begin{tabular}{|l|c|c|}
\hline Treatment group Ulcer healed & $\begin{array}{c}\text { Ulcer healed } \\
\text { No. }(\%)\end{array}$ & $\begin{array}{c}\text { Ulcer not healed } \\
\text { No. }(\%)\end{array}$ \\
\hline Medical & $38(76.0)$ & $12(24.0)$ \\
\hline Surgical & $48(96.0)$ & $2(4.0)$ \\
\hline X2 (p value) & \multicolumn{2}{|c|}{$8.306(0.004)$} \\
\hline O.R. (95\% CI) & \multicolumn{2}{|c|}{$7.57(35.71-1.597)$} \\
\hline
\end{tabular}

Table - 3: Distribution of patients with chronic anal fissure according to Treatment group and mean pain score at eight weeks

\begin{tabular}{|c|c|c|}
\hline $\begin{array}{c}\text { Treatment group } \\
\text { Pain score }\end{array}$ & $\begin{array}{c}\text { Pain score } \\
\text { Mean (+ SD) }\end{array}$ & $\begin{array}{c}\text { T test } \\
\text { (p value) }\end{array}$ \\
\hline Medical & $0.86+0.485$ & $2.693(0.008)$ \\
\hline Surgical & $0.26+0.527$ & \\
\hline
\end{tabular}

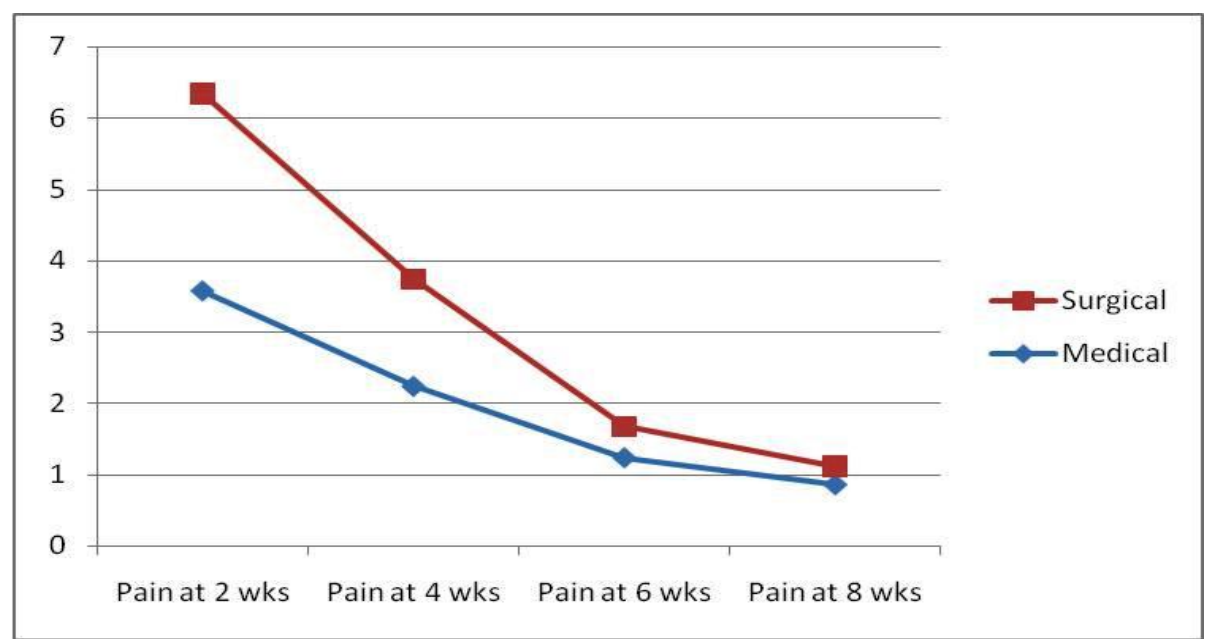

Figure-1: Mean pain score of patients according to treatment group at 2, 4, 6 and 8 weeks after treatment 


\section{DISCUSSION}

In this study the distribution of disease was mostly in the age group of $20-50$ years. $56 \%$ of the patients were male. The distribution differs from the standard literatures [1]. Mcdonald et al (1983) [2] =has shown a higher female percentage of patient of anal fissure, but other studies by Lock \& Thombson et al (1977) [3] the Birmingham series noted a slightly male preponderance. In our study pain during defecation was noted in $49 \%$ of patients. Lock \& Thombson et al (1977) [3] found pain and spasm to be present in $69 \%$ of patients. Location of fissure was found to be anterior in $10 \%$ and posterior in $90 \%$ cases and fissures was associated with sentinel piles in $37 \%$ of cases. But in the study conducted by Lock \& Thombson et al (1977) [3] the posterior fissure were in $75 \%$ of cases, anterior and lateral in $14 \%$ and $3 \%$ respectively. They have found the incidence of sentinel piles to be $38 \%$. But in the study conducted by Lund [4] the posterior anal fissure was found in $76 \%$ of patients and anterior fissure in $24 \%$ of patients. The proportion of anterior anal fissures is much higher in female patients being $21 \%$ compared with only $9 \%$ in male population [Lock \& Thombson et al (1977) [3]. The principal aim of both medical and surgical treatment is to decrease the tone of internal anal sphincter which subsequently results in increase in local blood flow leading to healing. Pharmacological agents employed include nitrates (isosorbide dinitrate or glyceryl trinitrate), calcium channel blocker (nifedipine, diltiazem), and botulinum toxin etc. Surgical method most commonly employed is finger dilatation and lateral internal sphincterotomy, later being regarded as gold standard [5]. Other surgical methods developed include fissurectomy, local flap procedures such as V-Y advancement flap and rotation flaps [6, 7].

Calcium channel blocker act by blocking the slow L-type channels causing smooth muscle relaxation thereby decreasing resting anal pressure. A prospective study conducted in 2002 in Queens medical centre UK established the fact that $2 \%$ Diltiazem is an effective and safe treatment for chronic anal fissure in patients who failed to respond to topical $0.2 \%$ GTN. However other study showed that topical Diltiazem was comparable to GTN in terms of healing (71\% healed) without side effects. Srivastava carried out same study in India and revealed the fact that Diltiazem cream also appears to cause lesser headache than GTN ointment without a significant difference in healing rates between the two agents [8]. As attenuation of anal resting pressure is temporary, the benefit of Diltiazem cream is not permanent in some patient. Healing rate of chronic anal fissures in various studies ranged from $47 \%$ to $89 \%$. The healing rate with $2 \%$ Diltiazem ointment seen in my study is $76 \%$. Anal dilatation has been considered an efficient simple procedure with rapid and effective symptomatic relief. It has a high recurrence rate and may cause uncontrolled tearing of sphincter, resulting in disturbed continence [9]. Fissurectomy with posterior internal sphincterotomy is considered less effective than lateral sphincterotomy. It has largely been abandoned because of presumed longer period of wound healing and higher incidence of disturbed continence [10].

Chronic anal fissure have traditionally been managed with lateral internal sphincterotomy. It promises rapid relief of pain and is simple to perform. It is treatment of choice in chronic anal fissure for many surgeons. In our study, the group treated by lateral internal sphincterotomy, there was significant pain relief at 2 weeks $(\mathrm{p}=0.005), 4$ weeks $(\mathrm{p}=0.009), 6$ weeks $(\mathrm{p}=0.004)$ and at 8 weeks $(\mathrm{p}=0.008)$.

Table 3 showed that pain reduction was significant $(\mathrm{p}=0.008)$ in surgical treatment group than in medical treatment group at 8 weeks. Oh et al [11] reported immediate relief of pain in $95 \%$ of those treated by open lateral internal sphincterotomy. Ho and Ho [12] reported relief of pain in $92 \%$ of patients after 2 weeks. In our study in the surgical treatment group, $96 \%$ of the patient showed complete healing of their fissure in 8 weeks. Hananal and Gordon [13] reported a healing rate of $84 \%$ in 4 weeks raised to $94.4 \%$ in 8 weeks. In our study ulcer healing at 8 weeks was significantly higher $(\mathrm{p}=0.004)$ in surgical treatment group $(96.0 \%)$ than in medical treatment group $(76.0 \%)$. In ulcer healing surgical treatment was almost 8 times more effective than medical treatment at 8 weeks. Varying degree of incontinence has been reported by different authors, more commonly observed in women. In our study 3 patients of surgical treatment group had fecal incontinence in first 6 weeks and by the end of 8 weeks only one patient had frank fecal incontinence. In other study there was also occurrence of incontinence in $8 \%$ to $30 \%$ of patients $[14,15]$. Therefore our present study corroborates well with the standard studies of comparative study of lateral internal sphincterotomy versus $2 \%$ Diltiazem ointment for treatment of chronic anal fissure which is well supported by several literatures.

\section{CONCLUSION}

Our study was designed to compare the effect of medical treatment by topical application of $2 \%$ Diltiazem ointment and surgical treatment by lateral internal sphincterotomy in case of chronic anal fissure with regards to ulcer healing, pain reduction, cessation of bleeding per rectum and incontinence.

The patients with chronic anal fissure were randomized either in medical treatment group or in surgical treatment group. Both the groups were evaluated at 2 weeks interval up to 8 weeks. In total 100 patients who participated the trial during the study, maximum patients found in the age group of 20-50 years with slight male predominance. Majority of the patients had presenting sign of ulcer and fair number ulcer with sentinel piles. 
Patients were evaluated at 2nd, 4th, 6th and 8th week for fissure healing, pain alleviation, bleeding per rectum and incontinence. Complete fissure healing was noted in $76.0 \%$ of patients in medical treatment group and 96.0 $\%$ of patients in surgical treatment group. In medical treatment group pain reduction was fairly good. The pain score (mean) falls steadily over 6 weeks. But the pain alleviation in surgical treatment group was excellent and quick and steep drop in pain score was noted in 1 st 6 weeks. Symptom of bleeding per rectum was similar in both groups and by 4 th week both groups had decrease in symptoms. From 4th week around none of the patients in both treatment groups had complained symptoms of bleeding per rectum. Our study establishes that Lateral Internal Sphincterotomy is the treatment of choice while treating chronic anal fissure, because of its simplicity, better healing rates, better patient satisfaction, minimal morbidity and low complication rates. Taking these options also helps the patient to resume his/her normal day to day activities earlier than that of use of topical 2 $\%$ Diltiazem ointment. Keeping in mind the simplicity, healing rates, patient satisfaction and morbidity the Lateral Internal Sphincterotomy is better than the use of topical $2 \%$ Diltiazem ointment. However the medical treatment is an option in patients who are unwilling to undergo surgical management.

\section{REFERENCES}

[1] K.P. Nugent. Benign Anal disease. In: Johnson CD, Taylor I (eds.) Recent advances in surgery. 25th ed. London, Royal Society of Medicine Press Ltd, 2002, PP 147-60.

[2] McDonald P, Driscoll AM, et al. The anal dilator in the conservative management of acute anal fissures. Br J Surg 1983; 70: 25-

[3] Lock MR and Thompson JPS (1977) Fissure in Ano. The initial management and prognosis BTS 64, 355-358.

[4] Lund JN, Armitage NC, Scholefield JH (1996) Use of Glyceryl trinitrate ointment in treatment of anal fissure Br J Surg 83(6): 776-777.

[5] Poh A, Tan Y, Seow- Choen F. Innovations in chronic anal fissure treatment: A systemic review. World J Gastrointest Surg 2010; 2: 231-41.

[6] Singh M, Sharma A, Gardiner A, Duthie GS. Early results of a rotational flap to treat chronic anal fissures. Int J Colorectal dis 2005; 20: 339-42.

[7] Giordano P, Gravante G, Grondona P, Ruggiero B, Porrett T. Lunniss PJ. Simple Cutaneous advancement flap anoplasty for resistant chronic anal fissure: a prospective study. World J Surg 2009; 33; 1058-63.

[8] Shrivastava UK, Jain BK, Kumar P, Saifee Y. A comparison of the effects of Diltiazem and Glyceryl trinitrate ointment in the treatment of chronic anal fissure: a randomized clinical trial. Surg Today 2007; 37: 482-5.

[9] Sohn N, Eisenberg MM, Weinstein MA, Lugo RN, Ader J. Precise anorectal sphincter dilatation- its role in the therapy of anal fissure. Dis Colon Rectum 1992; 35: 322-7.

[10] Dicastro A, Biancari F, D'Andrea V, Caviglia A. Fissurectomy with posterior midline sphincterotomy and anoplasty in the management of chronic anal fissures. Surg Today 1997; 27; 975-8.

[11] Oh C, Divino CM, Steinhagen RM. Anal fissure: 20 years experience. Dis Colon Rectum 1995; 38; $378-82$.

[12] Ho KS, Ho YH. Randomized clinical trial comparing oral nifedipine with lateral anal sphincterotomy and tailored sphincterotomy in the treatment of chronic anal fissure. Br J Surg. 2005; 92: 403-8.

[13] Hananel N, Gordon PH. Lateral internal sphincterotomy for fissure-In-Ano. Revisited Dis Colon Rectum 1997; 40: 597-602.

[14] Nyam DC, Pemberton JH. Long-term results of lateral internal sphincterotomy for chronic anal fissure with particular reference to incidence of faecal incontinence. Dis Colon Rectum 1999; 42: 1306-10.

[15] Garcia-Anguilar J, Belmonte C, Wong WD, et al. Open Vs. closed sphincterotomy for chronic anal fissure. Dis Colon Rectum 1996; 39: 440-3. 